\title{
Digitalization of education and the problem of continuity
}

\author{
Elena Sklyarova*, and Galina Kharlamova \\ Don State Technical University, 344000, Rostov-on-Don, Russia
}

\begin{abstract}
The trends in the modern educational process related to digitalization, the spread of information and communication technologies, the translation of information into the language of computer programming, the use of graphic visualization techniques, computer graphics are considered. There is a tendency to increase the methodological developments prepared by the pedagogical community, dedicated to techniques, optimization of the translation of a large amount of information. The formation of an open digital educational environment is characterized as a factor of external management of the formation of learning youth. It is emphasized that this trend only partially solves the problem of professional development of young people. It is proved that continuity is possible if translation and inheritance are considered as complementary types of human activity. Inheritance, however, is a multilevel process of human interaction with the surrounding world, affecting the structures of the unconscious, and is meaningful in connection with the implementation of external activities by a person according to the norms and standards set by culture. Such a specific nature of the language makes us doubt the universal possibilities of digitizing the knowledge to be assimilated.
\end{abstract}

\section{Introduction}

The concepts of digitalization, transformation, virtual reality, etc. today characterize educational activities, emphasizing the specifics of the pedagogical process, the activity of the position of specialists employed in the higher education system. Teaching teams have joined in updating projects aimed at improving the training of highly qualified specialists in the conditions of the dominant influence of such technical tools in Russian society, which are united by the term digitalization. This term refers to the spread of the practice of converting information into a number - a system of symbols and signs that acts as an analogue of the content aspect of education, as well as its aspects such as infrastructure, management, and regulation of behavior. Digitalization today reflects the fact of changing attitudes that regulate people's communication and interaction within society [1].

In general, digitalization can be considered one of the main resources that influence the transformation of education, the redistribution of the role of technology in order to improve the information and educational environment. Digitalization is associated with the

\footnotetext{
* Corresponding author: cklyarova2007@yandex.ru
} 
intensification of the educational process [2], a change in the hierarchy of social values, and a person's understanding of their identity. There are prerequisites for the emergence of a new type of students who are motivated for conscious personal development, who are inclined to independently determine their educational trajectory. The identified trends are a challenge to the Russian education system, its readiness to train a wide range of specialists in new professions who are prone to creative non-standard solutions and have developed communication skills.

Digitalization of education is a process created in the late $80 \mathrm{~s}$ of the twentieth century by the digital technological revolution. With the help of new media, a cognitive and communicative educational space has developed in the world. The world community was seized with the hope of expanding the dialogue opportunities that open up to people. Traditional educational practices were challenged.

In the practice of training specialists, complex tasks have arisen related to the development of such competencies as self-regulation of training, skills of production and synthesis of knowledge, creativity, project activity skills, and critical thinking. The media, it seemed, contributed to the displacement of passive consumers of information. The time has come for active users who can transform content and create new media products. The expectation of the results of the revolutionary changes in the sphere of "numbers" led to the emergence of descriptions of a new type of person - a person of art, or a creative consumer. Its distinctive features are associated with creative activity, the desire for self-expression, and interested participation in the production of products.

The system of educational institutions is changing, and the educational space is rapidly expanding, covering both local (at the level of the student group) and global (students and teachers within the university and beyond) levels of communities using various communication educational platforms. Students open a window into the cognitive world by showing search activity, interacting with their peers within the network space. Educational content is often co-authored by teachers and students in order to develop skills for accessing resources, developing the ability to analyze them, and evaluating their ability to create their own content.

In the educational space, the pedagogical community sees opportunities to improve the translation of knowledge, bearing in mind, first of all, the geography of its distribution, the possibility of reducing the time for checking tasks, determining the degree of independence of the work.

The community of teachers and students is encouraged by the fact that digital objects are carriers of diverse practices - written, visual, video, music, and computer. The ability of users to transform new media products, adjust their connotations. The problem of the fundamental instability of digital symbolizations is noted. They are not saved in the original version, but are modified according to the specific purpose specified by the user. Media tools are not very specific. Their metamediais demanded by the modern needs of creating remixes, combinations of forms and images, concentrated in the culture. The digital environment is created through the active participation of teachers to solve the problem of improving literacy. The so-called digital environments are designed to manage the independent work of students, the implementation of scientific projects. The acquired skills of using media tools can be applied by students in various fields of training.

The question of what the university's educational environment should be is being actively discussed today. What are the conditions for the possibility of its dynamism? What are the factors that ensure its role as a conductor and integrator of knowledge?

Recent research has focused on understanding the processes taking place in a modern university. They emphasize the dominance of feelings of increasing pressure of digitalization, information expansion. The ability to control the epistemological regime on the part of the teaching staff is called into question. The ability of teachers to remain a key 
link in the process of broadcasting educational content is lost. Education is increasingly functioning in a simulation mode. Visuality dominates students ' ideas about the real world, accumulating streams of existing meanings.

The situation in education today is characterized by the fact that visual evidence, an iconic code (a system of signs that has a certain natural similarity to the object to which it relates) and everyday language meet and actively interact in it. In other words, visual evolution in educational practices creates anxiety about the possible derealization of a person. Western educational practice supports this state of anxiety with its rationalized practice, which is characterized by the fragmentation of the world into existing and nonexistent, essential and non-essential, etc. Such practices immerse a person in an ostensive (Latin ostensivus visual) world in which nothing is said, they do not seek to maintain speech skills, and the existence of things is associated with evidence. Visual (visual) images merge with the language of everyday life, educational actions acquire a virtual character, the dialogue between the teacher and the student is deprived of psychological tension. The visual image in educational practice implicitly legalizes silence, deprives speech of the accompaniment of education. Knowledge begins to exist, preceding the effort to obtain it.

The problem of the meaning of pedagogical activity in the context of the rapid spread of portable computer tools and the expansion of the range of non-university educational services in general is aggravated. The development of information and computer technologies leads to the emergence of such a challenge to the university as virtual reality. The university is obliged to solve not only the instrumental task-to provide computer literacy of students for their subsequent orientation in the updated semiotic-symbolic environment. The virtual world influences the content of education, expanding the palette of traditional forms, including games, scientific research, art, etc. To solve the problem of students ' orientation in the virtual space, the university is currently called upon to develop the necessary conceptual apparatus, methodological support, and train the teaching staff.

Digitalization of education has affected the sphere of direct interpersonal contacts between Teachers and students. The weakening of such contacts occurs despite the installation of personality-oriented training that exploits the psychological resources of interpersonal relationships

Analysis of the processes associated with digitalization is also undertaken by the scientific community, performing theoretical developments of a fundamental nature. The concept of digital culture has been introduced into modern research practice. The author emphasizes its importance in the development of the issue of economic and, in general, national security of Russia.

Digital culture is understood as an emerging stage of culture, a digital society. The features of the latter are manifested in the digital economy, and the analog economy, characteristic of the previous social foundations, is overcome.

The understanding of digital culture in modern research is based on the ideas of culture as a value system that uses digital technologies and promotes social cohesion. In this context, digital technologies are considered as a system of encoding, information transmission, ensuring the implementation of diverse tasks in a short time. The author notes the problematic nature of the current socio-cultural situation, due to the insufficient mass distribution of digital technologies, the lack of clear prospects for their effective use. In the process of development is a general social model of the digital economy, the emergence of which is significant for modern youth, focused on economic activities in the emerging information space.

The idea of a digital economy is embedded in the idea of a digital society, and establishes the rationale for the ideas about the significant impact of the digital economy on modern society as a whole, including the education system. In the educational process, there are increasing trends in improving the conditions that contribute to the acquisition of 
user experience by students. Its expanded interpretation reflects the understanding of the emotional, intellectual, and sensory aspects of human interaction with technology as an integral aspect of his life. Human-computer interaction is characterized by the term "feeling in technology". The premise of this approach was the teachings of John Dewey and Mikhail Bakhtin, which prepared the direction of theoretical understanding of technology as experience.

In modern definitions of digital culture, one can see semantic accents that emphasize the reflection in it of artifacts, symbolic structures represented by digital coding. This feature of digital culture, according to the authors, determines its possibility of universal technical implementation in the institutional system, contributes to the maintenance of certain values that are fixed mentally. However, the focus on encoded artifacts and their effective use hinders the existence of culture as a system of meaning-based values, and its study as a factor in opposing universal digitalization. The latter is increasingly being evaluated as an obstacle to the preservation of the human principle in a person [3-14].

In this regard, the practice of continuity - the translation and inheritance of knowledge, socio-cultural experience in general-is of particular importance. Its theoretical understanding with the use of updated methodologies becomes problematic. In the new conditions, further in-depth research of the issues is required: what is continuity? How does knowledge transfer work? What are the conditions for the possibility of effective inheritance?

\section{Materials and methods}

Research methods. Within the framework of the undertaken interdisciplinary research, a general scientific methodology (empirical and theoretical methods) was used. Dialectical, comparative-historical and comparative-comparative methods helped to identify the essential characteristics of the process under study. Dialectical materialism aims at considering continuity as a necessary manifestation of the infinite process of selfdevelopment of matter, as an objective law of being reflected in the process of cognition. The attitudes of philosophical anthropology and the principles of hermeneutics contributed to the understanding of the practice of continuity as a human activity that affects its holistic development.

\section{Results}

The pedagogical community pays more and more attention to digital literacy of students, sees it as the main priority of training specialists. In other words, the activity of teachers seeks to develop the ability of students to use computer programming, graphic visualization techniques, computer graphics, multimedia, etc. A wide range of assessments was identified, reflecting the students ' ability to interact with digital technology, the degree of confidence in knowledge, the level of understanding of how the information flow spreads, what is a network community, what is social media.

It is noted that it is necessary to navigate the Internet content, to master the techniques of "numbers" for personal development. The main problem, which focused developers numerous recommendations on the elimination of illiteracy in the world of numbers is the question clear idea of studying the specifics of the digital space, it's possible to teach a person to control the noise, the ability to help the personal development of man, confront stressors. Having the opportunity to independently acquire knowledge, generating their own innovative knowledge, students are aimed at forming new competencies of the XXI century - creativity, critical thinking, communication, cooperation. The digital 
transformation of education can be accompanied by a "synergistic" content update, which will lead to a fundamental improvement in the quality of education. The modern period of computerization of the educational process is aimed at including all its subjects in the digital educational space.

In the formation of an open digital educational space, an important role is played by the organization of independent work of students, aimed at cultivating the ability of students to understand the conditions for the possibility of inheriting socio-cultural experience. The efforts of the modern pedagogical community are aimed at creating a type of educational environment that provides, mainly, the translation of knowledge.

However, full-fledged training of specialists involves the implementation of continuity, the condition for the possibility of which are two interacting activities - along with the translation of knowledge, skills, and abilities, inheritance is carried out. The inheritance activity is characterized by following the patterns stored in the culture. Within the framework of such an organized activity (in accordance with the norms and standards of culture), human organs arise due to the performance of certain functions. Inheritance involves the inclusion of a person in the totality of social relations, which also encourage actions consistent with the current situation [15].

A human ability is formed, which is characterized as social inheritance [15]. Only in the presence of this ability, as a specific relation of a person to the world, is it possible to develop other forms of the human psyche (consciousness, will, etc.).

The educational process is similar to the individual appropriation of various forms created in the culture. It can be understood as individual inheritance. In this case, not only the results of the activity (products) of the culture are inherited, but also the logic of their creation. Assignment is the same as inheritance. Appropriation means making one's own, or an activity conditioned by a person's consciousness and such a form of it as perception. Such activities are carried out by people connected by social relations, a type of which is relations in the field of education. By their own efforts, in a community with students, the student discovers patterns for themselves, building their actions according to them.

Thus, he builds for himself the territory that determines his personal development. The space of his freedom is formed, constituted by himself, determined by important, interrelated things, inherited experience, conditioned by the need to change the conditions of existence. The territory (space, area) is determined by the activity of the student, his need to change the conditions of existence, himself. There is a "discovery of the hidden" (Heidegger), as a result of which there are also updated ways of a person's stay in society, the educational system.

The practice of inheriting the achievements of mankind develops at those stages of the formation of culture, where the connection between people and lower animals is traced, the foundation of the conceptual thinking of man is laid, the prerequisites for the full implementation of continuity are born. The formation of subjective means of cognition in accordance with the evolutionary process of adaptation to the world is conditioned by the perception and actions of a person. The latter characterize the moment of adaptation of a person, precede the use of artificially created means, encoding and decoding of information, although such processes may not be realized by the subject, take place at the level of the unconscious. As an activity, perception is involved in the constitution of the space of possibilities, the active abilities of a person - all that determines the continuation of the process of humanization of culture.

Appropriation, understood as the acceptance of cultural achievements by a person, is associated with the perception of a person and the subsequent transfer to the property of their own inner world of the properties and essential characteristics of the object, the logic of its occurrence, allows us to characterize perception as a distribution of information. This means the possibility of considering perception as a special type of human activity, its 
behavior in the surrounding world. It is carried out according to the purpose, by appropriate means. Its result is characterized by awareness, change and transformation of the surrounding world. Perception, understood as the process of appropriating the experience of culture, mastering it, introducing it to the development of culture, is an activity through which the connection of generations, inheritance, is carried out. In the proposed context, the inheritance of socio-cultural experience, understood as the process of its appropriation, satisfies the main need of a person, is a condition for his ontogenetic development - the reproduction in the properties and abilities of an individual of historically formed properties and abilities of the human species, including the ability to understand and use language. Being a de-objectivation, perception accompanies the inheritance of human tacit knowledge, i.e. implicit, unarticulated knowledge in the language, embodied in bodily skills, perception schemes, acquired in direct communication. The cognitive-structural approach to perception helps to justify the existence of schemes, frames preceding the activity, correcting it, creating an ordered world of perception - the reality of perception, the content basis for combining impressions into a whole. Since empirical knowledge includes, in addition to personal experience, the experience of culture, perception actualizes the worldview representations of the past in unity with the present and the assumed future. Some "background" knowledge is formed, based on the amodal schemes of the world and the human body. Without being revealed, verbalized, it is characterized as personal knowledge that precedes the appearance of cognitive schemas and maps, serving as a criterion for new sensory data. Ontologically rooted formations that have not yet been presented to consciousness affect its content, for example, the corporeality of a person, instincts, archetypes, power, domination. The experience of perception is formed, in fact, already at the level of the continuous non-reflexive layer of consciousness, where there is no subject-object opposition, the conditions for the possibility of the cognitive process as such are formed, which determine the processes of inheritance associated with it. The content of the experience of perception is the existential experience, the layer of perception, its structural component of the experience of perception, its content aspect, the ontological basis of the experience of perception. It precedes object (theoretical) knowledge, is its basis and condition. Existential experience is acquired by any person, can dramatically affect his life, self-identification, open a new vision of reality, bypassing established ideas, standards. It actualizes a priori knowledge, turns it into concrete and meaningful knowledge [16].

The constitution of the educational space involves the involvement of a significant Other in the sphere of presence - one who is able, as Bergson wrote, " ... to open up to the flow. Confident in themselves, because they feel something better than themselves, they manifest themselves as great figures who are able to transfer human life to a different key". [17] They can contribute to the implementation of broadcast and not to interfere with the inheritance, while supporting a continuity in the culture.

\section{Discussion}

The digitalization of education has exacerbated the problem of continuity and related human activities, such as the transmission and inheritance of cultural experience. In studies devoted to this issue, the term succession itself is not always mentioned. Studying the development of culture, the interaction of the past with the present was characterized by the word progress. At the same time, the foundations for the formation of the problem of interaction between generations as an independent one within the social and humanitarian sciences have been formed for centuries, which is confirmed by the history of philosophy. Thus, the scientific development of continuity was undertaken by Hegel using the dialectical method. Continuity in the thinker's teaching is a fundamental concept that contributes more to the study of spiritual life, the self-development of the absolute spirit. 
Dialectical materialism presented a different vision of continuity. The latter is considered as a necessary manifestation of self-developing matter, a regularity of being. Man reflects this process in cognition.

According to the theories of Russian thinkers, continuity is found in the spatial-temporal interaction of the phenomenon of culture [18].

The whole, being a system, is able to change in the process of self-development. The old social order is being replaced by the new one. Such statements arise as a result of homogeneous analysis [19]. Another methodological approach, called heterogeneous, involves considering changes in culture caused by the interaction of different types of cultures. Analytical approaches that consider continuity separately in a specific area of human activity have become widespread. In particular, V. S. Bibler distinguishes continuity in the field of science and the arts [20]. Other authors emphasize the applicability of the term continuity to content when it comes to science. If one explores the sphere of art, continuity affects the art form. At the same time, there is no in - depth study of the concept of continuity as a form of human activity that combines two types of activity-not only translation, but also inheritance. Special attention should be paid to the analysis of processes related to inheritance in the practice of education. For a long time, there is no doubt about the possibility of full-fledged succession in the presence of inheritance. In other words, the condition for the possibility of a person's perception of socio-cultural experience should be his activity in accordance with the norms and standards inherent in culture. In the process of such historically determined inheritance, a person becomes a subject, a person. Genetically, a person has both organs and abilities as a result of his interaction with the outside world. Under the influence of external necessity, a person is included in social ties, relationships. The latter encourage him to act in a certain way.

\section{Conclusions}

The digitalization of education creates anxiety in the modern world about the danger of human transformation. The emerging trends encourage the search for factors to counteract the programming of human consciousness - all that suppresses his intellectual activity, reduces the range of thought. The task of preserving the integrity of a person is actualized, the solution of which involves its understanding from the standpoint of philosophy. Theoretical and methodological approaches of philosophical anthropology dictate the need to introduce the concept of educational space, which develops the connotations of the term educational space. The latter carries the characteristics of the created educational environment, an external phenomenon for students. The concept of the space of education contributes to the generalization of most of the prerequisites that determine the preservation of a person's personal characteristics, provides an opportunity for them to independently comprehend the fullness of their own internal activity. With the help of the concept of educational space, characterized as a sphere of cultural space, the inherent human ability to creatively interact with the world, representing integrity, is emphasized.

Putting forward inheritance as a philosophical term, the authors were guided by the attitudes of activity epistemology. In other words, we are talking about the interpretation of inheritance as a person's mastery of the ways of interacting with things. This is the mechanism of human entry into the world of culture, called " purely social inheritance of life forms.

In the process of education, the individual appropriation of the entire variety of historically formed ways of life should take place. The logic of their occurrence should also borrow.

The conducted research allows us to conclude that the terms of assignment and inheritance are interrelated (correlated). Appropriation, in fact, making one's own, is the 
activity activity of a person. The possibility of such activity is due to the human consciousness, which manifests itself in perception. The latter determines the actions of a person, which precede the use of both existing tools, and do not exclude the active processing of impressions, encoding and decoding of the received information. At the level of perception, such processes may not be realized by a person.

Appropriation, understood as self-acceptance, is associated with the perception of a person and the subsequent translation of the perceived qualities and essential characteristics of the object, the logic of its occurrence into their inner world. Perception performs the function of spreading out, that is, it becomes a special kind of human activity in relation to the surrounding world. It is carried out according to the purpose, by appropriate means. The activity of inheritance, which is possible in society, is provided through education, specially organized transmission of knowledge, skills, and abilities. This creates conditions for the possibility of continuity, supports the interaction of generations, and maintains the vitality of culture.

The study of the conditions for the possibility of inheritance contributes to the understanding of the processes that preserve the personal integrity of a person, the significance of the educational space. The authors of the study recognize the unity of the physical, mental and spiritual qualities of a person. Each of the aspects of its integrity determines the development of the others. The preservation of each of these facets, i.e., the comprehensive development of a person, or his integral development, strengthens his vital forces that support self-preservation. The unilateral development of any one of the facets of integrity, destroys its Formation, which is understood as the realization of a person's potential, will be full-fledged if the versatility of a person is taken into account, since each of his hypostases, developing, determines the development of the other, contributes to his integral entry into the world. The world is open to man through the senses, perception, reason, self-consciousness, reason. This role helps to perceive the world and how the purpose of the action, and as the wealth obtained from its predecessors.

The communication of generations, the establishment of a connection between them, takes place in the form of inheritance, which is a permanent way of reproducing the human image (or type) of life activity in new generations. Inheritance is a necessary condition for the possibility of a person's constant realization of the personal principle, due to the individual's involvement in active interaction in society, allowing him to develop his needs and abilities. The practice of inheritance of accumulated cultural values is rooted in the stages of the development of culture, where the indissoluble connection of people and lower animals is still noticeable, the foundation of the conceptual thinking of man was laid, the prerequisites for the full implementation of continuity were born. The subjective structures of cognition of the world are determined evolutionarily, by the process of human adaptation to the world.

Similarly, there is a design of the individual world of a person, associated with the degree of his education, due to the activity of the individual, his aspiration to overcome his own naturalness. The alleged appropriation of cultural property is accompanied by social communication - with contemporaries and predecessors. The actual process of communication is the inheritance (assignment) of forms of communication with a significant Other. Others are those people who enjoy unconditional spiritual and moral authority and are revered as mentors of humanity, revealing the meaning of life to people. They have received the name of a Teacher of Life, a spiritual teacher, are included in the connection of generations, and contribute to the formation of the sphere of human competence. The emerging cultural integrity and its component part-the space of educationrepresent the results of the activities of many participants. Its existence is conditioned by the fact that values are inherited, appropriated by a person, by generations of people. 
The results of the philosophical reflection presented in the article dictate the need to continue the methodologically updated understanding of the role of digital technologies in education. The importance of digitalization of education is currently determined by the function of technical support for training specialists. The promotion of digital technologies can aim at the successful formation of students ' personal characteristics in an expanded interpretation of the educational process as a way to maintain the continuity of generations. Under the condition of understanding continuity as an activity, the components of which are recognized as translational processes, balanced by the activity of inheritance - the individual appropriation of cultural experience by the individual. The solution of the problem involves significant practical and intellectual efforts, time spent by the pedagogical community, associated with the development of the content aspect of the broadcast content.

Otherwise, the reorientation of education to prepare students for passing test tasks will finally destroy the creative personality and the ability of a person to meet the challenges of the time.

\section{References}

1. N.P. Petrova, G.A. Bondareva, The World of science, culture, education 5 (78) (2019).

2. I.M. Aginova, Pomor University Bulletin 5, 128-134 (2010).

3. V. Bogoslovsky, A.L.Busygin, V.N. Aniskin, Samara scientific Bulletin. 8, 1 (26) (2019).

4. D.J. King, Higher education in Russia 1, (2015).

5. G. Ruckriem, Cultural-historical psychology 4, 30-38 (2010).

6. M. Cole, Cultural-historical psychology 7, 3-16 (2007).

7. V.A. Poshekhonova, Pedagogical education in Russia 5, (2018).

8. E.M. Nikolaeva, Izvestiya Saratovskogo un-ta, Nov. ser.Ser. Philosophy. Psychology. Pedagogy 17 (2), 162-166 (2017). DOI: 10.18500/1819-7671-2017-17-2-162-166.

9. C. Campbell, Journal of Consumer Culture 5, 1, 23-42 (2005).

10. V.M. Monakhov, Modern information technologies and IT-education 13, 2, 111-121 (2017).

11. S.K. Omarova, Pedagogy. Questions of theory and practice 1 (9), 78-83 (2018).

12. T.F. Kuznetsova, KNOWLEDGE. UNDERSTANDING. SKILL 4, 233-235 (2018).

13. N.V. Dneprovskaya, Statistics and Economics 15, 4, 16-28 (2018).

14. E.V. Gnatyshina, Bulletin of the Chelyabinsk State Pedagogical University 3, 46-54 (2018).

15. E.V. Ilyenkov, Philosophy and Culture (Politizdat, Moscow, 1991).

16. E.E. Nesmeyanov, G.S. Kharlamova, The problem of personality formation: identity, identification, Other (conceptual approaches G.G. Shpet, M.M. Bakhtin, SHS Web Conf. 70, 2019. Trends in the Development of Psycho-Pedagogical Education in the Conditions of Transitional Society (ICTDPP-2019) Published online: 22 November 2019 DOI https://doi.org/10.1051/shsconf/20197005005.

17. A. Bergson, The Two sources of morality and religion (Kanon, Moscow, 1994).

18. E.A. Baller, The Continuity in the development of culture (Nauka, Moscow, 1969).

19. E.A. Sklyarova, Humanities and social Sciences 3, 37-44 (2017).

20. V.S. Bibler, From science studies - to the logic of culture (Publishing House of Political Literature, Moscow, 1991). 